\title{
АВТОМАТИЗАЦИЯ БУХГАЛТЕРСКОГО УЧЕТА И БУДУЩЕЕ БУХГАЛТЕРСКОЙ ПРОФЕССИИ
}

\section{ОРИГИНАЛЬНАЯ СТАТЬЯ}

SUMAR, Ramiro Rodrigues ${ }^{1}$

SUMAR, Ramiro Rodrigues. Автоматизация бухгалтерского учета и будущее бухгалтерской профессии. Revista Científica Multidisciplinar Núcleo do Conhecimento. Год 06, эд. 06, Vol. 17, с. 167-181. Июнь 2021 года. ISSN: 24480959, Ссылка доступа: https://www.nucleodoconhecimento.com.br/бухгалтерскийучет/бухгалтерской-профрессии, DOI: 10.32749/nucleodoconhecimento.com.br/ru/91618

\section{СВОДКА}

Наличие качества в предоставляемых услугах действительно необходимо для выживания бухгалтерской профессии, поскольку оно переводится в цель бухгалтера. Информационные системы, новые технологии искусственного интеллекта и инновации, когда они связаны с экспертизой специалистов по бухгалтерскому учету, могут привести к повышению производительности компаний и, следовательно, экономики. Учитывая, что профессия бухгалтера стремится предоставлять налоговую информацию налоговым органам, данная статья призвана продемонстрировать, что эта профессия находится в процессе миграции в отношении автоматизации задач, чтобы стать инструментом управления, способным помочь в принятии решений, чтобы способствовать выполнению социальной ответственности компаний. Проблематизация данного исследования основана на следующем проблемном вопросе: Какова будет роль бухгалтера в автоматизации бухгалтерского учета? Закончится ли бухгалтерская

\footnotetext{
${ }^{1}$ Степень магистра в области контроля, специалиста в области управления технологиями, стратегического администрирования, информационной безопасности и выпускника в области бухгалтерских наук.
}

RC: 91618

Disponível em: https://www.nucleodoconhecimento.com.br/бухгалтерский-учет/бухгалтерскойпрофессии 
профессия, как предсказывал Институт Sapiens в исследовании 2018 года? Для достижения поставленных целей был использован обзор литературы. В качестве результатов в статье продемонстрирована роль бухгалтера в процессе развития и роста компаний до и после автоматизации бюрократических процессов, а также перспективы будущего сценария профессии. Таким образом, было установлено, что бухгалтерская профессия претерпевает внезапную смену позиционирования, чтобы выжить как профессия и сохранить свою роль в обществе и экономике страны.

Ключевые слова: автоматизация бухгалтерского учета, бухгалтерский учет профессионал, социальная ответственность, принятие решений.

\section{1. ВСТУПЛЕНИЕ}

Существует сценарий больших изменений на рынке бухгалтерского учета, с новыми технологиями, использованием искусственного интеллекта $и$ автоматизацией процессов. И наряду с этими изменениями существуют проблемы, тревоги и неопределенности, которые новое вызывает у людей (SOUZA et al., 2018).

Эти изменения в стране видят и ощущают все, где инфляция больше не считается проблемой, уровень безработицы снизился, доступ к кредитам и потреблению увеличился и, как следствие, снизился уровень бедности (CUNHA, 2019).

Таким образом, существует предпринимательский сценарий, в котором каждый день появляются новые компании и требуется больше профессионалов, но некоторые профессии рискуют не существовать из-за технологий и автоматизации (LEITE, 2017; ARAÚJO, 2020).

Согласно Rozenbaum (2018), исследование, проведенное в 2018 году Французским институтом Sapiens, показывает, что пять професссий находятся

Disponível em: https://www.nucleodoconhecimento.com.br/бухгалтерский-учет/бухгалтерской- 
под угрозой исчезновения, среди них - бухгалтер, работающий в офисе без доступа к технологиям, таким как использование компьютеров. .

Современному бухгалтеру, по-прежнему приходится иметь дело с бюрократической частью, законностью и большим количеством ролей, которые занимают пространство. Поскольку автоматизация процессов и другие пришествия для облегчения бухгалтерской работы происходят из технологий, специалисту по бухгалтерскому учету придется адаптироваться к использованию технологий в своих интересах или неохотно меняться и видеть, как его профессия исчезает до автоматизации (DINIZ, 2014).

Согласно исследованию фрранцузского института, число людей, превышающее два миллиона человек, «с большой вероятностью увидят, что их рабочие места исчезнут в ближайшие годы». Данные для исследования были из DARES (Служба статистических исследований Министерства труда Франции) и в нем, например, можно наблюдать, что банковские работники могут полностью исчезнуть к 2050 году, а бухгалтеры в 2056 году (ROZENBAUM, 2018).

Конкурентоспособность, проявляемая на рынке, когда предприниматели каждый день ищут инновации и новые технологии для расширения своего бизнеса, делает профессионала бухгалтерского учета встроенным в эту среду. Компании, столкнувшиеся с конкурентным рынком, не могут не иметь наряду с помощью бухгалтера, так как этот профессионал имеет в своей атрибуции цель к качеству и эффрективности во всех областях бизнеса (CHIAVENATO, 2004).

Другой момент заключается в том, что millennials захватывают рынок труда и завоевывают позиции в иерархии компаний и в принятии решений. Поэтому для профессионала в области бухгалтерского учета важно знать и понимать эту аудиторию, которая ожидает гибкости и качества в бухгалтерских услугах.

Однако целью данной статьи является изучение будущего бухгалтерской профессии и автоматизации, которая происходит в бухгалтерской работе. Эти изменения необходимы для удержания бухгалтера на конкурентном рынке, а

Disponível em: https://www.nucleodoconhecimento.com.br/бухгалтерский-учет/бухгалтерской- 
также его важности в создании новых рабочих мест, его способности к осуществлению и инновациям, а также социальной значимости перед его бухгалтерской и фискальной функцией.

Бухгалтерская профрессия переживает серьезные трансформации, перестав быть профессионалом, который приносит только проблемы и счета, а выступая в качестве опоры в управлении компаниями. С этой целью профессионал должен адаптироваться к новым требованиям и внедрять инновации, чтобы сохранить свою роль и важность не только для компаний и менеджеров, но и для общества, после своей социальной роли.

Методология, использованная при написании этой статьи, заключалась в библиографических исследованиях, исследованиях, книгах, журналах, интернетинтервью, интернет-статьях и опубликованных научных статьях. Для Gil (2008) библиографическое исследование разрабатывается на основе уже разработанного материала и составленного в основном из монографий, диссертаций, научных статей и книг.

Когда дело доходит до цели, Marconi и Lakatos (1992) объясняют, что библиографическое исследование дает наблюдателю возможность напрямую контактировать с материалами, написанными по предмету исследования, и помогать исследователю в его анализе или в момент манипулирования информацией. Библиографическое исследование рассматривается как первый шаг к началу научных исследований.

\section{2. ТЕОРЕТИЧЕСКАЯ СПРАВКА}

\section{1 ИСТОРИЯ БУХГАЛТЕРА}

Есть сведения, что фигура бухгалтера присутствует с начала цивилизации. Согласно ludícibus и Marion (2006, стр. 32): «[...] у самых примитивных народов бухгалтерский учет уже существовал из-за необходимости контролировать, 
измерять и сохранять семейное наследие и даже из-за обмена товарами для большего удовлетворения. людей $[\ldots] »$.

Несмотря на сообщения, официальное существование бухгалтерии было отмечено в современную эпоху, в 15-16 веках, в регионе Италии. В эпоху Возрождения профессия бухгалтера получила место в таких областях, как: экономика, искусство, наука и технологии (FIGUEIREDO; STRASSBURG, 2008).

В Бразилии, еще до появления первых коммерческих технических школ, бухгалтерский учет практиковался в лице «бухгалтера», профессионала, определенного в соответствии с Торговым кодексом 1850 года, который, согласно Francisco D'Auria (1949), отвечал за и регистрировали сделки коммерческих учреждений в то время (CARVALHO, 2017).

Развитие бухгалтерской профессии последовало за принятием Декрета-закона 9295 от 27 мая 1946 года, которым был создан Федеральный бухгалтерский совет и определены полномочия бухгалтеров, бухгалтеров и бухгалтеров (DOS SANTOS et al., 2019).

C советом профессия расширилась и возникло много проблем с уравниванием профрессионалов с разным уровнем образования и знаний. Если, с одной стороны, есть бухгалтер, обученный на курсе бакалавриата, то профессионал без какого-либо обучения сосуществует в одной профессии (NETO, 2010).

Это вызвало незаинтересованность молодежи в бухгалтерском учете, так как статус этой профессии был не таким, как у других образований, таких как право и экономика. Как пробудить интерес к профессии, которая представляет уровни профрессионалов, противостоящие друг другу? Это было возможно только при наличии доказательств квалификации и отделения от специалиста по бухгалтерскому учету до самого бухгалтера.

В 1972 году аудит регулировался Постановлением $n^{\circ} 220$, а также циркулярами $n^{\circ} 178$ и nº 179 Центрального банка Бразилии. Он ввел демонстративные

Disponível em: https://www.nucleodoconhecimento.com.br/бухгалтерский-учет/бухгалтерскойпрофессии 
стандарты, которые требовали, чтобы сертифицированные лица адаптировали специалистов к аудиту (ABREU, 2013; CORDEIRO, 2011).

Однако бухгалтерская профессия получила статус только в декабре 1976 года с принятием Закона № 6404, известного как закон SA (Sociedades Anônimas Анонимное общество). Этот закон породил Бразильскую комиссию по ценным бумагам (CVM), которая заменила Центральный банк, в отношении выдачи заключений и части законодательства о бухгалтерском учете, а также контроля над рынком капитала в Бразилии (CARVALHOSA, 2017).

Для Santos (2008, стр. 9)

[...] В последние годы, особенно после окончания эпохи высокой инфляции, с середины 1990-х годов, она претерпела период больших изменений и адаптаций. Компании, которые были более гибкими в адаптации своего фокуса к своему основному бизнесу, своему основному бизнесу $и$ больше не управляли инфляционными доходами и доходами, достигли более высоких показателей успеха. И, на данный момент, специалист по бухгалтерскому учету имеет основное участие в предоставлении налогового, корпоративного и финансового руководства. [...]. Счетчик, все чаще, является компасом компании.

Отмечается, что требования к навыкам и навыкам специалиста по бухгалтерскому учету сосредоточены на стратегиях и принятии решений в компаниях. В связи с технологическими изменениями правительства, компании и менеджеры находятся в высокой степени инноваций, все более требовательных к профессионалам в области бухгалтерского учета, которые, в свою очередь, помогают в принятии решений (DE OLIVEIRA REIS et al., 2015).

В высококонкурентной и гибкой среде безопасное получение информации является диффреренциалом. Точность и надежность также требуются современным компаниям, которые хотят обеспечить свое выживание на рынке и сделать фигуру бухгалтера богатым специалистом по данным и бухгалтерским записям, требуя от него знать, как интерпретировать данные и наметить

Disponível em: https://www.nucleodoconhecimento.com.br/бухгалтерский-учет/бухгалтерской- 
стратегии и пути, которые обеспечивают лучшие результаты. Все эти требования противоречат тому, что Santos (2008, стр. 10) пишет в своей книге:

[...] счетчик не должен терять из виду, что бухгалтерия не для него, а для пользователя. Бухгалтерский учет - это язык бизнеса, и этот язык рассказывает историю каждой компании. Совершенствование этого языка, стремящееся увеличить его способность прогнозировать и полезность для пользователя, является, пожалуй, основной миссией бухгалтера. [...]

Поэтому профрессионал должен находиться в процессе обучения, обновления и образования, чтобы быть экспертом в своей роли и в получении данных, которые помогают корпорации в ее социальной цели. Легкий доступ к аспирантуре в области бухгалтерского учета дает человеку возможность позиционироваться рядом с рынком, чтобы внести свой вклад в компании, экономику и общество.

\section{2 ЭКОНОМИЧЕСКОЕ РАЗВИТИЕ И РОСТ}

Furtado (1964) определяет экономическое развитие как «процесс социальных изменений, посредством которого все большее число человеческих потребностей удовлетворяется за счет дифференциации в производственной системе в результате внедрения технологических инноваций».

Для Hewlett (1981) экономическое развитие определяется как «значительное увеличение реального дохода на душу населения в стране с целью получения лучшего питания, здравоохранения, образования, лучших условий жизни и все более широкого спектра возможностей для работы и отдыха для людей этой страны».

С другой стороны, существует экономический рост, который, по мнению Siedenberg (2006), состоит из «процесса изменений преимущественно количественного характера, означающего увеличение размера, объема и/или количества». Резюмируя то, что заключил Vasconcellos (2000), указав, что экономический рост - это непрерывный рост дохода на душу населения в течение определенного времени.

Disponível em: https://www.nucleodoconhecimento.com.br/бухгалтерский-учет/бухгалтерской- 
Рост и поддержание валового внутреннего продукта (ВВП) способствуют повышению качества жизни населения. Кроме того, технологические инновации, увеличение национального дохода, расширение рабочей силы и сбережений являются другими фракторами, которые помогают экономическому росту страны.

Отмечается, что когда страна демонстрирует экономический рост, число безработных уменьшается, в то время как собираемые налоги увеличиваются. В этом контексте необходимо инвестировать больше для поддержания продолжающегося роста экономики. Mendes (2015) объясняет, что экономика и рост родителей были неэффективными из-за некоторых факторов, включая образование и высокую налоговую нагрузку.

В соответствии с экономическим ростом происходит экономическое развитие, для существования которого стране необходимо поддерживать показатели и иметь фракторы для улучшения качества жизни и доходов населения с течением времени. Для Rocha (2004) эти фракторы демонстрируют: рост экономического благосостояния, измеряемый экономическими показателями, среди которых справедливо упомянуть общий национальный продукт и национальный продукт на душу населения; снижение уровня нищеты, безработицы и социальной жизни; и расширение здравоохранения, питания, образования и жилищных условий.

Индекс человеческого развития (ИЧР) Организации Объединенных Наций $(\mathrm{OOH})$ - это единица измерения, созданная и используемая для проверки степени развития данной страны, включая здоровье, образование и доход. Индекс - это числовая ссылка, вариация которой определяется между 0 и 1, в ее определениях, чем ближе значение к 1, тем лучше должно быть развитие этого места в представленных элементах. Ни в одной стране ИЧР не установлен равным нулю или хотя бы единице (FILGUEIRA et al., 2010).

Согласно докладу ООН, в котором есть оценка 189 стран, Бразилия достигла 0,761 пункта в 2018 году, что представляет собой значительный рост по сравнению с 2013 годом, где она получила 0,752.

Disponível em: https://www.nucleodoconhecimento.com.br/бухгалтерский-учет/бухгалтерской- 
Бразилия занимает 79-е место в рейтинге, наряду с Колумбией и входит в категорию стран с высоким уровнем человеческого развития. В докладе самым высоким показателем является Норвегия с 0,954 балла, а с наихудшим индексом человеческого развития указан Нигер с 0,377 (LEUSIN JÚNIOR, 2015).

\section{3 НОВЫЕ ТЕХНОЛОГИИ В УЧЕТЕ}

Новые технологии в конечном итоге порождают структурные изменения в организациях с их применением, влияя на затраты компаний и модифицируя их производственные процессы с учетом конкурентоспособности на рынке (МАТ, 2010).

Scott (2009) подчеркивает, что использование технологий в бухгалтерском учете - беспрецедентное изменение, то есть нелегко определить, было ли его влияние отрицательным или положительным. С другой точки зрения, Alsharayri (2011) и Choe (2004) показывают, что уровень технологий и производимой информации оказывает положительное влияние.

Технологии положительно влияют как на гибкость, так и на надежность и безопасность информационных систем, используемых в компаниях бухгалтерскими бюро и профессионалами. Функция информации, генерируемой системами, согласно Allahyari и Ramazani (2011), состоит в том, чтобы помочь пользователям принимать решения, учитывая, что бухгалтерский учет может производить соответствующую информацию для формулирования бизнеспроцессов и стратегических процессов, для контроля деятельности и для роста компаний.

Для Scott (2009) преимущество технологии заключается в использовании нескольких инструментов для ускорения выполнения функций, выполняемых счетчиком. В этом аспекте технология способствует оперативному развитию бухгалтерского учета в условиях конкурентоспособности, учитывая скорость и эфффективность, предлагаемые технологическими достижениями.

Disponível em: https://www.nucleodoconhecimento.com.br/бухгалтерский-учет/бухгалтерской- 
Acevedo (2012) показывает, что если коммуникации в бухгалтерских компаниях будут быстрыми, они могут помочь повысить производительность, а также улучшить принятие решений и способствовать росту бизнеса.

Также, по словам Scott (2009), одним из недостатков технологии является ее зависимость от человека. Технология возникает из человеческих инноваций, поэтому это продукт, который повторяет одни и те же человеческие ошибки. Но это можно обойти с помощью более надежных процессов и с более целенаправленной специализацией и образованием по автоматизации. Это также демонстрирует, что еще одним недостатком является зависимость профессии от технологии, но уже известно, что исследования показывают, что счетчик, который существовал для операционализации расчетов, исчезнет, что противоречит этой ошибочной мысли автора.

Aribaba et al. (2011), в свою очередь, подчеркивают важность, которую технологии добавляют обществу, особенно в небольших сервисных компаниях, учитывая улучшение производительности и большее развитие бизнеса. Таким образом, с большей производительностью возникает больше возможностей и выгод, с этим создаются рабочие места и выигрывает экономика.

Конкурентоспособность требует, чтобы бухгалтерские организации могли создавать ценность для своих клиентов. Это клиенты, которые являются налогоплательщиками и штатные подрядчики. По словам Simons (1987), диффреренцируя себя от своих конкурентов, реализуя и фрормулируя четко определенную бизнес-стратегию, эти организации добавят больше результатов. В стратегии важное значение имеет использование технологий, добавленных в системы учета, поскольку она обеспечивает безопасную и полезную информацию (JERMIAS; GANI; 2004).

Наличие четко определенной и консолидированной стратегии, основанной на инвестициях в технологии и квалификации людей, по мнению Grande et al. (2011),

Disponível em: https://www.nucleodoconhecimento.com.br/бухгалтерский-учет/бухгалтерской- 
принесет продуктивные преимущества и благоприятные изменения для своих клиентов по сравнению с конкурентами.

\section{4 РОЛЬ БУХГАЛТЕРА В ИННОВАЦИЯХ И АВТОМАТИЗАЦИИ УЧЕТНЫХ ПРОЦЕССОВ}

Количество бухгалтерских контор увеличивается и способствует снижению безработицы в период с 2009 по 2012 год, согласно Gondim (2014). Произошло увеличение более чем на $60 \%$ офрициальных рабочих мест и на $5 \%$ в новых бухгалтерских фирмах.

Федеральный бухгалтерский совет (CFC, 2014) публикует на своем веб-сайте результаты опроса, который показывает, что более 58\% профессионалов бухгалтерского класса предпочитают работать в частных компаниях или открывать собственный офис вместо того, чтобы сдавать экзамен. и войти в государственный сектор. Обратите внимание, что эти данные показывают вклад в создание числа официальных и неформальных рабочих мест, поскольку бухгалтер работает с менеджерами компаний (их клиентами), сотрудничая с ними, так что бизнес развивается и растет, и ему нужно больше сотрудников.

Помогая предпринимателям или инвестируя в собственный бизнес, используя полученные практические и теоретические знания, бухгалтер играет значительную роль в экономике. В последние годы бухгалтерский учет перестал использовать только калькулятор и качи бумаги (NOGUEIRA, 2010).

Посмотрите, как Coelho (2015) объясняет, что бухгалтер больше не тот, кто фриксирует прошлые фракты, чтобы быть стратегическим консультантом с перспективным и широким взглядом на рынок. На основе этих изменений миссия контактора заключается в автоматизации процессов, повышении производительности и составлении статистических данных для поддержки компаний и менеджеров в принятии решений. 
Fávero et al. (2006) показывают, что «бухгалтерский учет направлен на получение информации для различных пользователей, чтобы они могли принимать решения». Эта цель кажется простой, но субъективные фракторы, вовлеченные в нее, затрудняют этот процесс, сложность понимания данных и дистанцирование бухгалтера менеджера затрудняет выполнение этой цели. Давайте посмотрим, что есть переменные для хорошего общения, и их необходимо изучить и по специальности бухгалтера, чтобы его цель, как специалиста по бухгалтерскому учету, была достигнута.

Поскольку целевая аудитория бухгалтерской информации выявляет новое поколение, которое нуждается в достоверной информации и требует, чтобы она была быстрой, наталкивающаяся на Drucker (1987), конкретная задача предпринимателя-менеджера компании заключается в том, чтобы сделать бизнес этой компании более гибким и качественным.

Согласно данным, доступным на веб-сайте CFC (2014), в Бразилии в настоящее время насчитывается более 71008 бухгалтерских организаций / компаний и 515 011 специалистов, зарегистрированных в Федеральном совете по бухгалтерскому учету, и эти специалисты и офисы должны быть подготовлены к автоматизации процессов.

Имея функцию бухгалтера направлять менеджеров к росту своих компаний, этот профессионал также играет важную роль в обществе, и для этого, всегда должен быть в поиске обновления своих знаний и вести себя этично, будучи собеседником правительства, с налогоплательщиком и обществом (CORONADO, 2017).

Бухгалтер, который направляет своих клиентов на правильный вклад, помогает в развитии государства и вместе с тем в развитии страны. В этой роли автоматизация является ключом ко всему вниманию бухгалтера именно в генерации информации, а не в скучных и трудоемких задачах конференций и релизов. 
Компетентность, профессионализм, ловкость и специализация тех, кто участвует в процессах, делают их более последовательными, гибкими и правильно фрункционируют. Эфффективная и специализированная бухгалтерская практика это тот момент, на который следует обратить внимание и которые становятся все более эффективными и конкурентоспособными.

Профрессионал, который понимает эти поведенческие изменения, которые происходят, специализируется и обновляется, будет иметь важную и решающую роль в обществе и корпорациях. Весь процесс зависит от человека, и это, человек должен иметь навыки и навыки для того, чтобы автоматизированный процесс работал должным образом, в дополнение к системным знаниям компаний. Специализация и глубокие знания являются инструментами для этой новой парадигмы изменения в бухгалтерской профессии.

\section{3. ЗАКЛЮЧЕНИЕ}

Как сказано в этой статье, бухгалтерская профессия с самого начала важна для развития и роста страны. Автоматизация бухгалтерских процессов и изменение требований профессии заставят погаснуть профессионала, который сегодня рассматривается только как соблюдающий требования законодательства. Затем появляется возможность для профессии и профессионалов выделиться в других областях своих знаний, таких как консалтинг и бизнес-стратегия, вкладывая обширные знания, полученные в образовании, в обучение.

Бухгалтерские конторы вносят свой вклад в создание рабочих мест, тем самым выполняя свою социальную роль, но должны адаптироваться к новой динамике информационных систем, чтобы они были эффрективными и качественно и оперативно производили информацию, необходимую для компаний и правительств. Поскольку образование является фундаментом развития любой нации, совершенствование профессии и воспитание профессионала влечет за собой значительное улучшение базы общества, а вместе с ним и мероприятия социального и профессионального совершенствования.

Disponível em: https://www.nucleodoconhecimento.com.br/бухгалтерский-учет/бухгалтерской- 
Специалист по бухгалтерскому учету перестал быть тем, кто приносит только плохие новости компаниям, с гидами и кредиторской задолженностью, обеспечивая стратегическую ориентацию предпринимателям и менеджерам, способствуя тому, чтобы они выполняли свои функции правильно и с той ловкостью, которая требуется рынку через правильные данные и извлекая быстро.

Contador обладает всеми инструментами и знаниями для автоматизации подготовки фринансовой отчетности и релизов, чтобы обеспечить большую гибкость и надежность, таким образом, становится союзником для компаний, чтобы играть свою социальную роль с ростом бизнеса.

Компании, растущие прочно, разумно и выполняющие свои налоговые и корпоративные обязательства с качеством и гибкостью, роль, которую бухгалтер может играть вместе с руководством, заставят развиваться все общество. Если каждый будет выполнять свою роль в экономике и обществе, будут созданы новые рабочие места, будет платиться больше налогов, снизится уровень бедности и будет выше предложение образования.

Угроза несуществовать профессию заставит профессионалов переосмыслить себя и пересмотреть свою позицию перед лицом инноваций. Те, кто по-другому рассматривает свою позицию как профессионала в области бухгалтерского учета, сочетая с новыми технологиями искусственного интеллекта, автоматизации и специализации, получили место на рынке, отличное от профессионала, который не обращает внимания на изменения и борется с ними.

С другой стороны, необходимо улучшить бухгалтерское образование, с тем чтобы новые технологии использовались в преподавании и чтобы стажеры покидали университеты, готовые столкнуться с современным миром, который требует гибкости и качества в предоставлении услуг.

Пробел, который необходимо изучить, наблюдается в отношении демографического распределения специалистов по бухгалтерскому учету,

Disponível em: https://www.nucleodoconhecimento.com.br/бухгалтерский-учет/бухгалтерской- 
учитывая степень инновационности компаний в определенных регионах. Это даст более широкое представление о том, что может или не может произойти с карьерой. Также предлагается проводить кейсы в инновационных компаниях с высокой степенью автоматизации и позиционированием профессионала по отношению к этой компании и ее результатам. Эти исследования будут способствовать более широкому пониманию того, что может произойти в будущем.

\section{РЕКОМЕНДАЦИИ}

ABREU, E. N. de. Regulamentação de auditoria: estudo da influência das fraudes contábeis de 2001. Goiânia: Universidade Federal de Goiás - UFG, 2013.

ACEVEDO, L. Business benefits of information technology. Chron, 2019. Disponível em: <http://smallbusiness.chron.com/business-benefits-informationtechnology-4021.html . Acesso em: 10/mai/2021

ALLAHYARI, A.; RAMAZANI, M. Firm technological change and its effects on management accounting change: case study of Iranian manufacturing firms. Global Journal of Management and Business Research, v. 11, n. 9, 2011.

ALSHARAYRI, M. A. The E-Commerce impact on improving accounting information system in Jordanian Hotels. International Research Journal of Finance and Economics, v. 75, 2011.

ARAÚJO, F. M. de. A inteligência artificial e os seus impactos no mundo do trabalho. Fortaleza: Centro Universitário Fametro, 2020.

ARIBABA, F. et al. An evaluation of the impact of technological innovative entrepreneurial development programmes on the performance of small scale business in Nigeria. Global Journal of Business, Management And Accounting, v. 1, n. 1, 2011. 
CARVALHOSA, M. de S. B. Comentários à lei de sociedades anônimas. Saraiva Educação SA, Editora: Saraiva Educação S. A., v. 1. 2017.

CFC. Conselho Federal de Contabilidade. Dados estatísticos do Conselho Federal de Contabilidade. 2014. Disponível em: http://www.cfc.org.br/. Acesso em: 12/mai/2021.

CHIAVENATO, I. Empreendedorismo: dando asas ao espírito empreendedor. Editora manole, 4ํㅡㄹ ed. 2004.

CHOE, J. Impact of management accounting information and AMT on organizational performance. Journal of Information Technology, v. 19, 2004.

COELHO, J. M. A. Contabilidade: uma carreira em transformação. Disponível em: http://www.portalcfc.org.br/noticia.php?new=23196. Acesso em: 12/mai/2021.

CORDEIRO, C. M. R. Auditoria e Governança corporativa. Editora: IESDE, 2011.

CORONADO, O. Contabilidade gerencial básica. Editora: Saraiva Educação SA, 2017.

CUNHA, E. S. Oferta de crédito e emprego local nos municípios da região Nordeste: 2002-2015. Salvador: Federal da Bahia. 2019.

D'AURIA, F. Primeiros princípios de contabilidade pura. São Paulo: Departamento de Cultura e Ação Social, 1949.

DE OLIVEIRA REIS, A. et al. Perfil do profissional contábil: habilidades, competências e imagem simbólica. Revista Contemporânea de contabilidade, v. 12, n. 25, p. 95-116, 2015.

DINIZ, E. R. da S. et al. Governança eletrônica no Brasil e o papel das tecnologias da informação e comunicação. Florianópolis: Universidade Federal de Santa Catarina, 2014. 
DOS SANTOS, M. J. A. et al. Um estudo comparativo entre o exame de suficiência do conselho federal de contabilidade, o exame nacional de desempenho de estudantes e a pós-graduação stricto sensu dos cursos de ciências contábeis do Estado do Rio de Janeiro. Polêm!ca, v. 13, n. 4, p. 1681-1698, 2014.

DRUCKER, P. F. Inovação e Espírito Empreendedor: prática e princípios. São Paulo: Pioneira, 1987.

FAVERO, H. L. et al. Teoria e Prática. 4 ed. Editora: Atlas, São Paulo. 2006.

FIGUEIREDO, C. R.; STRASSBURG, U. A Contabilidade: aspectos históricos que influenciaram no seu desenvolvimento no decorrer do tempo. IX Jornada de Estudos Contábeis-UNIOESTE, 2008.

FILGUEIRA, J. M. et al. Um panorama estatístico de cunho econômico, social e educacional do estado do Rio Grande do Norte. HOLOS, v. 4, p. 198-215, 2010.

FURTADO, C. Dialética do Desenvolvimento. Rio de Janeiro, $2^{a}$ ed., Fundo de Cultura, 1964.

GIL, A. C. Métodos e técnicas de pesquisa social. 6. ed. São Paulo: Atlas, 2008.

GONDIM, A. MEl também tem obrigações fiscais. Contábeis, 2016. Disponível em: https://www.contabeis.com.br/noticias/26714/mei-tambem-tem-obrigacoes-fiscais/.

GRANDE, E. U. et al. The impact of accounting information systems (AIS) on performance measures: empirical evidence in Spanish SMEs. The International Journal of Digital Accounting Research, v. 11, 2011.

HEWLETT, S. A. Dilemas do desenvolvimento. Rio de Janeiro: Zahar, 1981.

IUDÍCIBUS, S. de; MARION, J. C. Introdução à teoria da contabilidade para o nível de graduação. 4 ed. São Paulo. Editora: Atlas, 2006. 
JERMIAS, J.; GANI, L. Integrating business strategy, organizational configurations and management accounting systems with business unit effectiveness: a fitness landscape approach. Management Accounting Research, v. 15, 2004.

LEITE, E. F. O fenômeno do empreendedorismo. Saraiva Educação SA, 2017.

LEUSIN JÚNIOR, S. A inserção internacional de potências médias: evidências da afirmação de países em desenvolvimento a luz da evolução do sistema multilateral de comércio. Porto Alegre: Universidade Federal do Rio Grande do Sul, 2015.

MARCONI, M. de A.; LAKATOS, E. M. Metodologia do trabalho científico. São Paulo: Editora Atlas, 1992. 4a ed.

MAT, T. Z. Management accounting and organizational change: impact of alignment of management accounting system, structure and strategy on performance. Philosophy School of Accounting, Finance and Economics Faculty of Business and Law Edith Cowan University. Perth Western Austrália, 2010.

MENDES, M. Por que a economia do Brasil foi para o buraco? Brasil economia e governo, 2015. Disponível em: http://www.brasil-economiagoverno.org.br/2015/08/25/por-que-a-economia-brasileira-foi-para-o-buraco/. Acesso em: 14/mai/2021.

NETO, O. R. M. A profissionalização do contador no Brasil. São Paulo: Mackpesquisa, $2010 . \quad$ Disponível em: http://168.197.92.160/bitstream/handle/10899/14605/721_2008_0_15.pdf?sequence =1\&isAllowed $=\mathrm{y} /$. Acesso em: 14/mai/2021.

NOGUEIRA, M. Práticas de contabilidade: relatório de estágio do Mestrado em Gestão. Coimbra: [s.n], 2010. 
RAMALHO, T. C. L. Contabilidade criativa: a percepção dos Técnicos Oficiais de Contas. Lisboa: Instituto Superior de Contabilidade e Administração de Lisboa. 2015.

ROCHA, F. J. M. Educação e economia: uma abordagem sobre as consequências e condicionantes econômicas do desenvolvimento humano, com ênfase em educação. Brasília: Cadastro de Finanças Públicas, n. 5, 2004.

ROZENBAUM, S. Revolução digital deixa cinco profissões à beira da extinção. rfi, 2018. Disponível em: https://www.rfi.fr/br/economia/20180829-revolucao-digitaldeixa-cinco-profissoes-beira-da-extincao-diz-estudo.

SANTOS, R. F. dos. Introdução à contabilidade: noções fundamentais. São Paulo: Saraiva, 2008.

SCOTT, W. The impact technology is having on the accounting profession. World conference on higher education, 2009.

SIEDENBERG, D. R. Dicionário do Desenvolvimento Regional. Santa Cruz: Edunisc, 2006.

SIMONS, R. Accounting control systems and business strategy: an empirical analysis. Accounting, Organizations and Society, v. 12,1987.

SOUZA, E. C. et al. As características qualitativas da informação contábil a partir da percepção dos profissionais de contabilidade. In: Congresso UFPE de Ciências Contábeis. 2018.

VASCONCELLOS, M. A. S. de. Economia Micro e Macro: Teoria e Exercícios, Glossário com 260 Principais Conceitos Econômicos. São Paulo: Atlas, 2000.

Представлено: Август 2020.

Утверждено: Июнь 2021. 